\title{
Antropología del turismo de San Juan del Sur Rivas Nicaragua
}

Anthropology of tourism in San Juan del Sur, Rivas Nicaragua

Sandra Espinoza Vallejos

Especialista en Turismo Cultural- Consultora,

Docente, Maestrante en Antropología y

Liderazgo Social

ID Orcid: https://orcid.org/0000-0003-3239-7615

elidariana07@gmail.com

\author{
Ramiro García Vásquez \\ Biólogo, especialista en Antropología física y \\ Arqueología - Consultor, Docente. \\ Miembro Honorario de la Academia de Geografía \\ e Historia de Nicaragua \\ ID Orcid: https://orcid.org/0000-0003-2186-5452 \\ mamutsrgv@yahoo.es
}

Recibido: 22-08-2018

Aceptado: 20-09-2018

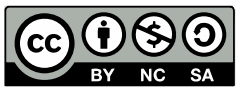

\section{Resumen}

El ensayo presenta un análisis de la antropología del turismo de San Juan del Sur desde sus orígenes hasta la modernidad, la comunidad está localizada en el Departamento de Rivas, Nicaragua y es considerada el más importante destino turístico de sol y playa en el Pacífico de nuestro país. Como sustento analítico se revisaron los resultados de investigaciones antropológicas, arqueológicas, históricas y datos cuantitativos actualizados a cerca del auge y desarrollo turístico en la comunidad. Los análisis que se hicieron a través de la antropología del turismo permitieron estudiar esta actividad económica, desde la relación que tiene con una amplia diversidad de grupos humanos, entre visitantes y residentes, que interactúan entre sí y como consecuencia se originan una serie de contactos basados en la interculturalidad que permite una mejor comprensión, sostenibilidad y aprovechamiento del turismo, re direccionándolo a tipologías vivenciales y comunitarias.

Palabras claves: Antropología, Multiculturalidad, Turismo, Desarrollo.

\begin{abstract}
The essay presents an analysis of the tourism anthropology of San Juan del Sur from its origins to modernity, the community is located in the Department of Rivas, Nicaragua and is considered the most important tourist destination of sun and beach in the Pacific of our country. As an analytical support, the results of anthropological, archaeological, historical and updated quantitative data were reviewed in relation to the boom and development of tourism in the community. The analysis that was made through the anthropology of tourism allowed to study this economic activity, from the relationship it has with a wide diversity of human groups, between visitors and residents, which interact with each other and as a consequence a series of contacts based on in interculturality that allows a better understanding, sustainability and use of tourism, redirecting it to experiential and community typologies.
\end{abstract}

Keywords: Anthropology, Multiculturalism, Tourism, Development 


\section{Introducción}

El presente Ensayo titulado: Antropología del Turismo de San Juan del Sur-Rivas, Nicaragua tiene la finalidad de analizar la principal actividad económica de esta comunidad portuaria, que es el turismo de sol y playa; basándonos en la interculturalidad originada en las relaciones de grupos humanos entre visitantes y locales que históricamente ha convergido en este lugar. Existe evidencia de que la actividad turística en este espacio es muy antigua; tomando en cuenta que por su posición geográfica ha sido punto de encuentro para diferentes culturas.

Se reconocen como primeras oleadas migratorias a los grupos mesoamericanos desde unos 1000 años a. J.C., posteriormente arriban los navíos peninsulares dirigidos por el conquistador Andrés Niño en 1522; le siguen las grandes oleadas de aventureros de todo el mundo que movidos por el fenómeno de la Fiebre del Oro en California (EEUU), realizaron el viaje desde Nueva York hasta San Francisco, pasado por La Ruta del Oro o del Tránsito en Nicaragua, en la que el Gobierno de José Laureano Pineda Ugarte confirmó al Puerto de San Juan del Sur como su terminal en la mar del sur, este evento confirmó el primer auge del turismo masivo y el origen de la multiculturalidad en la comunidad.

La guerra nacional dejó un monumento arquitectónico e histórico, junto a otras evidencias como restos del Telégrafo, la All América Cable y la Comunicación Radial; El Ferrocarril fue el principal medio de transporte para el auge del Cabotaje que inició en 1940, actividad que transformó al Puerto de San Juan del Sur en el más importante para el comercio nacional. Los pobladores actuales expresaron de viva voz, diferentes opiniones sobre el apego por su patrimonio natural y cultural; a la vez que reconocen que el turismo ha formado parte importante de la economía de su comunidad a lo largo de su historia; sin embargo sienten que se ha masificado y que el estilo de plantas turísticas que se han construido han cambiado irreversiblemente el entorno comunitario en el que ellos crecieron.

La antropología del turismo en San Juan del Sur, es un tópico importante para poder comprender la estructura sociocultural y el desarrollo económico de esta comunidad; para analizar el turismo desde los protagonistas se han revisado de las fuentes primarias recopiladas por los Cronistas de Indias, historiadores contemporáneos y periodistas, posteriormente se analizaron los resultados de investigaciones arqueológicas que reportan evidencias etnológicas de los primeros grupos que poblaron la comunidad, además se reflexiona en los testimonios recopilados a través de la antropología y el método etnográfico.

Reflexionando sobre las características del turismo masivo y los requerimientos donde se impone la homogenización globalizada de la industria turística neocolonial e imperial; se realiza la importancia de hacer propuestas de tipologías de turismo vivencial y comunitario que sean más amigables con la interculturalidad, el desarrollo sostenible, el medio ambiente y la originalidad comunal.

\section{Antropología del turismo de San Juan del Sur basado en sus orígenes comunitarios.}

La antropología es la ciencia que estudia el ser humano y sus relaciones. Por lo tanto existe una vinculación directa entre la antropología cultural y la antropología del turismo. Tal como lo define Kottak la antropología del turismo estudia al hombre, su evolución y las culturas humanas, describiendo y explicando, analizando e interpretando, sus similitudes y sus diferencias; tomando en cuenta que el turismo es un fenómeno característico de la contemporaneidad, un signo de nuestro tiempo que irrumpe e impregna la vida desde que se extiende por las sociedades con una mentalidad de ocio y consumo. (Kottak, 2002).

Todos nacemos en una sociedad determinada, la cual se ha ido desarrollando a través del tiempo y de la historia. Parafraseando el concepto del Dr. Alipio Sánchez Vidal, para que exista un origen comunitario debe tener un sistema o grupo social de raíz local, diferenciable en el seno de la sociedad de que es parte en base a características e intereses compartidos por sus miembros y subsistemas que incluyen: localidad geográfica (vecindad), interdependencia e interacción psicosocial estable y sentido de pertenencia a la comunidad e identificación con sus símbolos e instituciones. (Sánchez, 1991).

La población de San Juan del Sur reconoce sus orígenes comunitarios ancestrales. El profesor Rodolfo Muñiz de 60 años, se considera un historiador local de San 
Juan del Sur y un aficionado de la arqueología. En una entrevista nos comunicó de viva voz, que conoce muchos yacimientos arqueológicos en el municipio y que resguarda cuidadosamente una colección de fragmentos de cerámica precolombina, porque él reconoce que su comunidad tiene orígenes muy antiguos y que esos pueblos dejaron como herencia los vestigios de cerámica que está resguardando. (Muñiz, 2017).

Quito-Ecuador a finales de 1997 con la Ponencia titulada Los Patrones Alimenticios en el Pacífico Sur de Nicaragua. (García, 1977).

Basados en la antropología, arqueología e historia sabemos que los orígenes primarios comunitarios de San Juan del Sur están en las culturas mesoamericanas Oto mangue, Chorotegas y Uto Aztecas -Nicaraos, los que son reconocidos por los pobladores

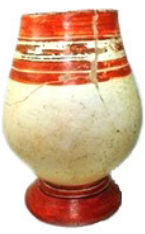

Papagayo

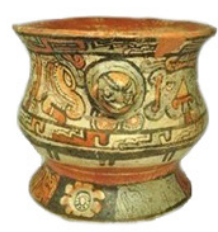

Vallejo

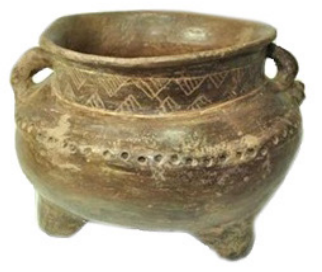

Castillo esgrafiado

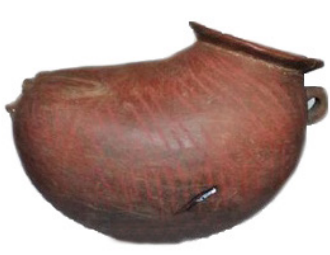

Sacasa estriado

Cerámica ancestral de cultura Oto -Mangue Chorotega y Uto-Azteca Nicarao. Foto Ramiro García actuales como sus ancestros, de los que conservan la comunalidad, que según la profesora María Teresa Romero es un rasgo de identidad que impregna la dinámica de vida de los habitantes originarios de los pueblos, que

Hurgando los orígenes de la comunidad en las fuentes históricas del historiador Miguel León Portilla cita: Alrededor del año 1200 (d.J.C.) vinieron a Centroamerica nuevas oleadas de poblaciones mesoamericanas del tronco lingüístico Uto -aztecas, náhuatl, que pasaron por el Golfo de Chorotega y avanzaron hasta el Pacífico Sur en el territorio de lo que actualmente es el Istmo de Rivas; ahí desplazaron a poblaciones de cultura Chorotega - Oto Mangue que habían llegado antes que ellos y se vieron obligados a emigrar más al sur. (Portilla, 1972).

La arqueología confirma las fuentes históricas, entre los meses de enero a marzo del año 1995, arqueólogos del Instituto Nicaragüense de Cultura (INC), auspiciados por La National Geography, realizaron reconocimientos, prospecciones y excavaciones arqueológicas en los sitios; El Ostional, Montemar y La Flor, ubicando 13 yacimientos, recolectando materiales culturales que sugieren una cronología entre 300 años (a.J.C). hasta 1,350 (d.J.C.). Los análisis de laboratorio, indicaron que los grupos aprovecharon los recursos faunísticos tanto marinos como terrestres para su dieta cotidiana y el desarrollo de su economía, sociedades y cultura. Los resultados de estas investigaciones fueron presentados en el $49^{\circ}$ Congreso de Americanista, celebrado en se expresa de manera particular en las actividades que se desarrollan cotidianamente para la realización de las celebraciones comunitarias y como parte de la organización social de cada pueblo. La identidad comunitaria da sentido y mantiene la cohesión social. (Romero, 2009).

Como expresión de esta identidad comunitaria y el sentido de pertenencia, los pobladores de San Juan del Sur gustan de hacer uso de los espacios públicos y privados por igual, tanto en los predios familiares como en las plazas, atrios y calles realizan su trabajo comunitario, sus comidas y sus fiestas colectivas, tradiciones religiosas; entre otros, esto se ha convertido en atractivos turísticos de evento; para el segmento de visitantes que gusta participar de sus procesiones de la Virgen del Carmen en barcos a orillas de la costa, de la elección de la reina en sus fiestas patronales, o de presentaciones artísticas en las plazas donde hacen derroche de alegría con el folclore de su departamento; en todas estas actividades no falta la comida típica, bebidas tradicionales y música nacional. 


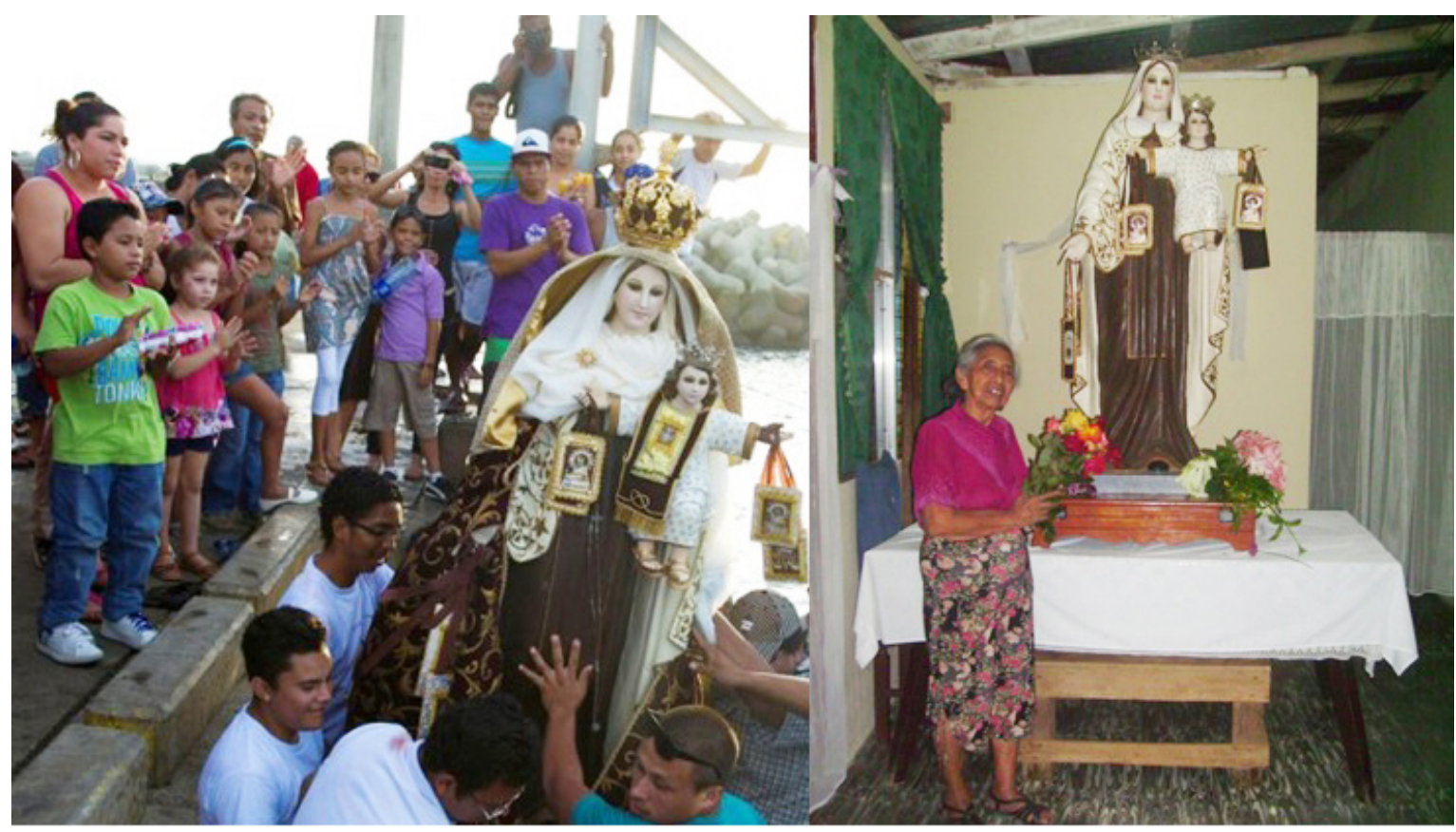

Comunidad de San Juan del Sur celebrando a la Virgen del Carmen. Foto Sandra Espinoza

\section{San Juan del Sur y su Multiculturalidad}

La multiculturalidad comunitaria en San Juan del Sur inicia en 1522, cuando el Puerto Natural que hasta entonces era aprovechado por los Chorotegas y Nicaraos para la pesca de autoconsumo; fue descubierto por el Capitán Andrés Niño, Piloto Real de La Casa de Indias que llegó navegando por el Mar Pacífico, procedente de Castilla del Oro, hoy Panamá y fue quien lo llamó San Juan de La Mar del Sur, de donde se deriva su nombre actual; además lo incorporó según sus leyes invasoras a la Corona española; por lo que se convirtió en el Primer Puerto Colonial de Nicaragua. (Sanchez, 1977).

En las crónicas se encuentra una de las mejores descripciones del puerto en la época colonial; fue recopilada de una carta escrita el 23 de enero de 1620 por el conquistador español Diego de Mercado dirigida a su Majestad el Rey Don Felipe III, cita así: El puerto de San Juan de la mar del Sur, que no hay en el dicho camino más de un cerrillo junto a la mar, que sin dificultad lo pueden andar carretas,; es hondable y está en tierra muy sana y se puede fortificar a poca costa, porque en él hay gran cantidad de maderos y mucha piedra con que hacer cal y buena tierra con que hacer teja y ladrillo, y así mismo tiene el di- cho puerto cerca de sí muchas praderas muy deleitosas, abundantísimas de pastos para el sustento de las boyadas y recuas que han de servir en el dicho trajín y carreteo. Tiene así mismo buenas aguas y el temple de la tierra es muy sana y saludable; y corre la costa del dicho puerto de noreste á sureste y está en trece grados poco más o menos. De San Juan de la mar del Sur todo tipo de mercadería irán en carretas entoldadas, en que se asegurarán de todo punto daños y averías, que, como dicho es de tierra no son más de cuatro leguas. $Y$ así mismo estoy informado de muchos pilotos y hombres de mar muy piráticos, como son Gaspar de Palacios, español, Jácome Promontorio, veneciano, y Simón Zacarías, flamenco, y de otros muchos que han navegado entre ambos mares. (Gámez, 1993).

Esta carta permite tener una visión, primero del entorno ambiental y la belleza natural de la bahía; algo que lamentablemente se ha sacrificado para dar lugar a las infraestructuras turísticas globalizadas; que contrastan con el entorno comunitario; otro aspecto es el cambio socioeconómico que sufrieron las comunidades autóctonas en el periodo de invasión colonial; ya que como dice David Luna Desola el mestizaje no fue más que un proceso violento de violación a las mujeres originarias, despojo de territoriales y otros abusos. (Desola, 1977) 
La carta muestra claramente como San Juan del Sur pasó de ser un puerto de navegación interna para los pueblos autóctonos a convertirse en un puerto internacional que permitía el arribo de embarcaciones de diferentes nacionalidades; es decir se abrieron las puertas al mundo. Diego de Mercado habla de la presencia de españoles, venecianos y flamencos. También menciona la introducción de nuevos medios para el desarrollo de la economía comunitaria como las carretas, el ganado vacuno y caballar que permitían la movilización de los productos agrícolas en mayor volumen y menor tiempo; los barcos de vela entre otros.

Lo anterior dio las pautas para un nuevo proceso socioeconómico donde se mezclaron los aportes de la cultura autóctona con las foráneas; dando origen a una comunidad multiétnica y multicultural en San Juan del Sur.

El método etnográfico permitió analizar la memoria colectiva para intentar encontrar los orígenes de la multiculturalidad, al entrevistar al Sr. Salomón Danglar Alvares de 82 años, nos dice que sus abuelos fueron el francés Germán Danglar y María Zapata que era de origen local. Según le contaba su padre Bruno Danglar, su abuelo había emigrado desde Francia para trabajar en el Canal de Panamá, pero después decidió venirse a Nicaragua para residir en el Puerto del Sur que para inicios de 1900 tenía mucho auge comercial. (Danglar, 2013).

Don José Jesús Lugo Tablada nos hizo un recorrido por la comunidad señalando las casas con más de 100 años de antigüedad, habló de las familias fundadoras tanto las que tienen un origen local como los extranjeros, al quedarse a vivir en ella junto a sus familias y negocios. Mencionó apellidos como; Lugo, Tablada, Canizales,
Hernández, Solís, Rivas; la casa de los Belli está en lo que fue la calle de la línea del Ferrocarril. Después muestra la tornaleza; explicando que ese era el lugar donde los rieles del tren le permitían dar la vuelta. Muy cerca de la tornaleza recuerda a la familia Palacios y más delante de los Cárcamo -Jarquín, la familia Cortez y los Carcache, Sandino, Granja y los Urcuyo que vendieron su casa a unos canadienses.

Refiriéndose a los apellidos de extranjeros menciona a los Cordón de origen alemán, los Morice de origen Italiano, los Danglar vinieron de Francia, los Kelly, los Holmann y Thompson, de origen inglés; En la calle central de la comunidad portuaria señala las casas con influencias victorianas como la de Carlos Holmann Morice, la de la Familia Michelle, la Casa de Ernesto Kelly que fue vendida al Dr. Morice y la casa de Mr. Cross, Gerente de la American Cable que actualmente es el Hotel Victoriano. (Tablada, 2013).

Según el concepto de Miguel Argibay la multiculturalidad desde la antropología cultural. Significa que se constata la existencia de diferentes culturas en un mismo espacio geográfico y social. Sin embargo estas culturas cohabitan, pero influyen poco las unas sobre las otras y no suelen ser permeables a las demás. Se mantienen en guetos y viven vidas paralelas. La sociedad de acogida suele ser hegemónica y establecer jerarquías legales y sociales que colocan a los otros grupos en inferioridad de condiciones, lo que lleva al conflicto, al menosprecio, a la creación de estereotipos y prejuicios dificultando la convivencia social, siempre en detrimento de los grupos más débiles. En los casos en que exista equidad y respeto mutuo se puede pasar de la multiculturalidad al multiculturalismo. (Argibay, 2009). En base a esto podemos afirmar que en San

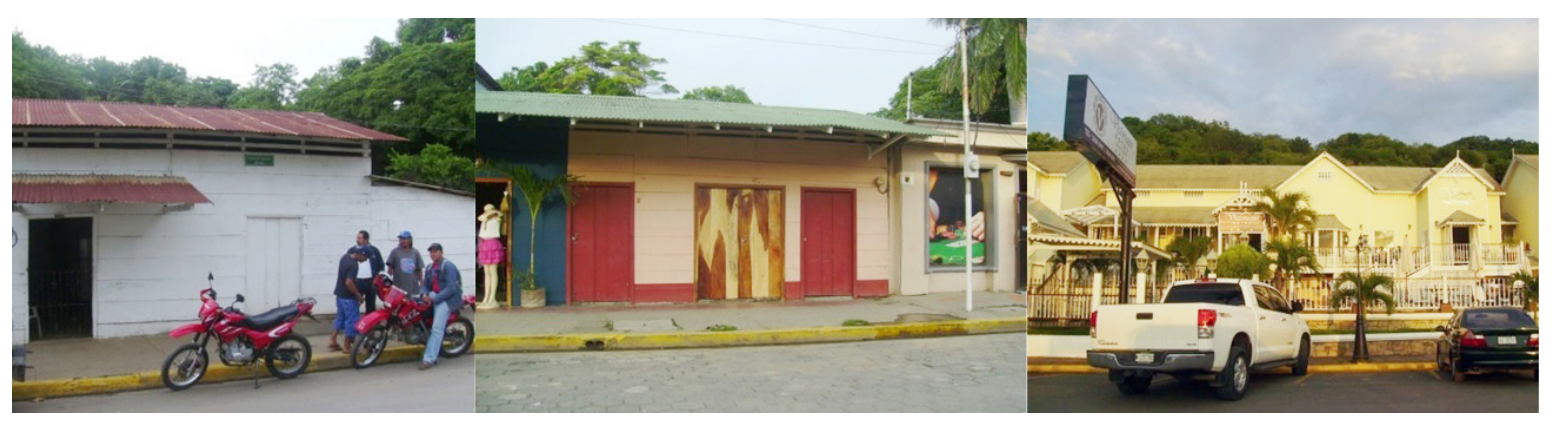

Casas con mas de 100 años en San Juan del Sur. Foto. Sandra Espinoza 
Juan del Sur existe multiculturalidad y que esto ha ejercido una gran influencia en los modelos capitalistas del turismo que se desarrolla en la comunidad.

\section{Orígenes del turismo en el Puerto de San Juan del Sur}

Los seres humanos a lo largo del tiempo han realizado migraciones, algunas temporales y otras definitivas. Sus desplazamientos han sido por razones variadas; necesidad, curiosidad, conocimiento o descanso; a estos viajes que las personas hacen por esparcimiento, recreación y ocio, es a lo que se le ha llamado Turismo. Miguel Alemán en 1977 anota que la palabra proviene del inglés "to tour" que significa salir de excursión y se deriva del viejo término francés tour con su primer significado de torno y con el extensivo de paseo y viaje. (Alemán, 1977).

Uno de los eventos históricos del S. XIX, que marcó el inicio del turismo internacional en la comunidad de San Juan del Sur, fue conocido como la Fiebre del Oro, una migración en masa y apresurada de personas de todo el mundo hacia el oeste de los (EEUU), motivada por el hallazgo de yacimientos auríferos en los alrededores de la ciudad de San Francisco. Las causas de estas migraciones se debieron, en gran parte, a un entorno de insatisfacción social favorecido por las esperanzas de que un golpe de suerte cambiara sus vidas y a las mejoras de las redes de comunicaciones y transporte interno, pero principalmente externo; con las ofertas de canales o rutas interoceánicos por Centroamerica. En este contexto surge La Ruta del Oro o del Tránsito.

El canal interoceánico por Nicaragua ha sido un sueño que han abrazado las potencias colonialistas e imperios neocoloniales a lo largo de nuestra historia; en 1849 George Ephraim Squier fue enviado como encargado de asuntos plenipotenciarios para América Central y logra que el Gobierno de Nicaragua otorgue una concesión a su Gobierno (EEUU) para que Cornelius Vanderbilt, junto con Nathaniel S.H. Wolf, organizaran la «American Atlantic and Pacific Ship Canal Company», la que inició estudios topográficos para la construcción de un canal transoceánico por el Río San Juan, lago Cocibolca y el Itsmo de Rivas. Los estudios de factibilidad no fueron alentadores y finalmente no se consiguió el capital para las obras del canal, sin embargo el multimillonario Vanderbilt aprovechó la concesión para dar apertura a lo que llamó La Ruta del Oro o del Tránsito y vender pasajes de transporte desde New York pasando por Nicaragua, y llegando a San Francisco. En 1851 el Gobierno de Laureano Pineda confirma el Puerto de San Juan del Sur como terminal de La Ruta del Oro o del Tránsito en la mar del sur.

Según los reportajes por Harpers Weekly, Journal of Civilization, en 1852, más de 10 mil pasajeros viajaron de Nueva York a California y en 1854 lo hicieron 13,218 pasajeros, todos pasaron o pernotaron en el Puerto de San Juan del Sur. Según Frank Leslie's en el diario Newspaper; la comunidad portuaria empezó a beneficiarse por el arribo de las masivas migraciones de todas partes del mundo; que requerían servicios, cita: Para ese entonces no había desembarcaderos o muelle en San Juan del Sur, los vapores anclaban a una milla o menos de la costa, sus pasajeros desembarcaban utilizando los botes propiedad de los nativos y por uno o dos dólares era llevados a la costa en donde los esperaban más nativos en estado de sami-desnudez, que por otros 25 centavos eran llevados a cuesta, a través del agua para "botarlo" en tierra firme y ahí les ofrecían sus bestias en alquiler para que cruzaran la franja de tierra desde San Juan del Sur hasta el Puerto de La Virgen. Las mujeres ofrecían productos alimenticios como frutas, bebidas, comidas a precios económicos y servicio de hospedaje para aquellos viajeros que tenían que esperar a los vapores que venían desde Panamá para hacer su parada en San Juan del Sur. (Leslies, 1976).

La Organización Mundial del Turismo (OMT) define al visitante como toda persona que viaja voluntariamente dentro de su territorio nacional o a un país distinto, siempre que el motivo principal de la visita no sea el de ejercer una actividad que se remunere en el sitio visitado. El viajero será llamado excursionista cuando permanezca en el destino menos de 24 horas y turista si se queda más de una noche, pero menos de un año en el lugar. Cuando la persona se desplaza a lugares de su país de origen se denominará turista nacional y si viaja fuera de las fronteras de su patria, se considerará turista extranjero.

En base al concepto, los viajeros de la Ruta del Oro o del Tránsito eran los que llegaban a la comunidad y en menos de 24 horas salían rumbo a San Francisco en las embarcaciones, o con dirección al puerto de La Virgen 
montados en mulas o caballos. Se pueden reconocer como turistas los viajeros que pernotaban por una o dos semanas esperando que llegaran las embarcaciones; en ese tiempo dejaban parte de su dinero a la comunidad local. Esta actividad migratoria que por sus características puede ser llamada turismo, requirió de la primera planta turística en la comunidad que es definida como las instalaciones físicas necesarias para el desarrollo de los servicios turísticos, como establecimientos que vendan hospedaje y alimentos.

Parafraseando a Leslie's, formaban parte de la planta turística; la Tienda de Mr. Green, hombre norteamericano que se estableció en San Juan del Sur desde 1852, como corredor de negocios y fue propietario de un hotel que era muy reconocido en San Juan del Sur, porque alquilaba amahacas a un dólar. La Taberna de A Rial del Cónsul Francés; era el lugar preferido de los norteamericanos para tomar bebidas alcohólicas y comer. Este diario también recopila notas de algunos pasajeros como el norteamericano Harris Newamark que escribió. "No se produjo ninguna apreciable variación de la temperatura mientras estaba yo en Nicaragua y en San Juan del Sur, cuya bahía es muy antigua, un pueblito hispanoamericano con una sola calle principal, por donde deambulé de arriba abajo matando el tiempo, el calor era sofocante y la gente con frecuencia dormía a la intemperie. (Leslies, 1976).

Otro aspecto importante para la naciente actividad turística de mediados de 1800 en San Juan del Sur fue

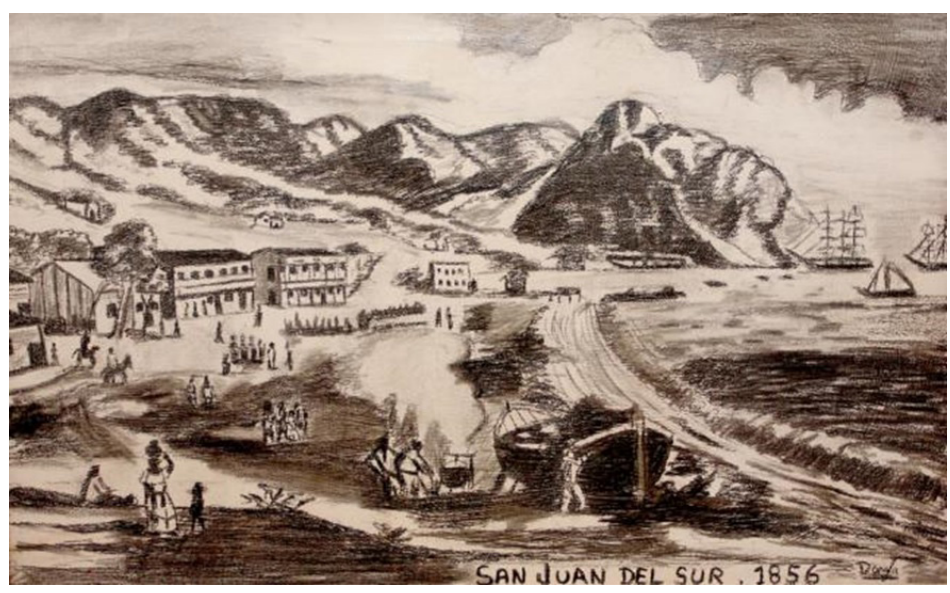

Retrato de la comunidad de San Juan del Sur del año 1856. Foto. Tomado del libro Newspaper de Frank Leslie's la infraestructura o el conjunto de elementos básicos necesarios para el funcionamiento de un centro poblado urbano o rural, su existencia es vital para el desarrollo del turismo. Retomando a Frank Leslie's, parte de estos elementos fue un camino macadamizado entre La Virgen y San Juan del Sur que mandó a construir Cornelius Vanderbilt en 1852. También fue de gran importancia para la infraestructura, el negocio del alemán Enrique Gottel, que alquilaba bestias de carga como mulas y caballos a los viajeros, logrando tanto éxito que en 1861, su economía le permitió alquilar cómodas diligencias (carruajes halados por caballos).

\section{Recursos patrimoniales para el desarrollo turístico en San Juan del Sur}

El Patrimonio es definido como aquello que es propio y se divide en dos grandes ramas; el Patrimonio Natural está formado por todos los recursos, la tierra, el agua, flora, fauna y el Patrimonio Cultural es integrado por elementos tangibles e intangibles. Lo tangible son las evidencias observables a la vista humana que representan la cultura de una sociedad o comunidad en un tiempo pasado; pueden ser objetos móviles o inmuebles. Lo intangible está en la memoria colectiva comunitaria y se refleja en prácticas, costumbres, creencias y tradiciones que fueron transmitidas de generación en generación en un mismo espacio geográfico y que les diferencian de otros grupos sociales. (Carro, 2007)

El patrimonio natural de San Juan del Sur tiene paisajes muy bellos, una hermosa bahía, clima tropical, la vegetación es el bosque seco tropical y bosque húmedo tropical en las áreas más elevadas, la flora ha sido lo más impactado históricamente y en relación a la fauna conservan áreas donde aún se pueden observar especies de aves, mamíferos y reptiles; siendo lo más representativo la fauna acuática.

El patrimonio cultural tangible mueble e inmueble se ha formado con los restos culturales que quedaron de las diferentes etapas históricas que ha vivido la comunidad; los más antiguos son los vestigios de puentes del camino macadamizado de la Ruta del Oro 
o del Tránsito. Este camino iba desde San Juan del Sur hasta La virgen. Los vestigios son considerados históricos y datan de 1852, uno de los más interesantes es el Puente de Arco, descrito por Leslie's en el Newspaper. (Leslies, 1976). Los vestigios se conservan "In Situ". El profesor Rodolfo Muñiz historiador local, conserva una pieza única que consiste en una "Placa de Bronce" de La Compañía Accesoria del Tránsito en Nicaragua. Esta la colocaban en los baúles de los viajeros cuando se trasladaban entre San Juan del Sur y el Puerto La Virgen y viceversa, el profesor dijo que si hubiera un museo en su comunidad los donaría para el disfrute de todos.
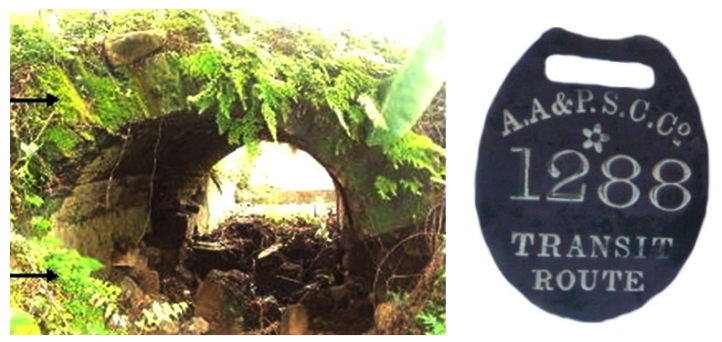

Vestigios de la ruta del oro o del tránsito. Puente de arco y placa de bronce. Foto, Ramiro García

La guerra nacional dejó un inmueble conocido como La Fortaleza El Vigía, fue mandada a construir por el invasor William Walker en 1856, cuando se posicionó de San Juan del Sur y decretó un estado de guerra. Citando a Frank Leslie's, el esclavista Walker obligó a ciertos pobladores de San Juan del Sur a triturar rocas y subirlas hasta la colina donde se estaba haciendo la construcción. También mando a instalar dos cañones para la defensa y el control de los buques de guerra. (Leslies, 1976) .La fortaleza se conserva In Situ, pero los cañones y bolas están en manos de personas de la comunidad.

En 1870 se inició el tendido telegráfico desde San Juan del Sur hasta Corinto, algunos pobladores aun resguardan restos de ese primer telégrafo. En 1882 se hizo la instalación de un cable submarino cuyo servicio era administrado por la All American Cable, el cual se mantuvo hasta los años 1960 para la comunicación de Nicaragua con el mundo; también se conservan vestigios materiales del cable y las casas de estilo victoriano que pertenecieron a esta empresa internacional. En

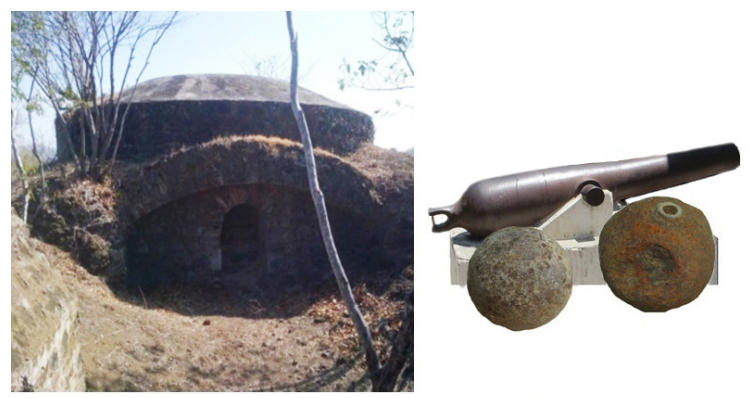

Fortaleza El Vigía con su cañón y balas. Foto Ramiro García

marzo de 1928 se inauguró la Red Ferroviaria entre San Jorge y San Juan del Sur, que establecía el contacto con el interior del país por medio del Vapor Victoria que hacia la travesía entre San Jorge y Granada; la población conserva fotografías del tren y del tanque donde cargaba combustible y pitaba para despues entrar a la calle principal hasta llegar al puerto donde descargaba los productos que traían del interior del país para exportarlos y cargaba los productos importados para llevarlos hasta donde serían comercializados. A partir de 1940 San Juan del Sur pasa a ser el Puerto del Cabotaje, por donde se realizaban toda clase de exportaciones e importaciones, uno de los vestigios más interesantes de esta época es El Faro de Cabotaje.

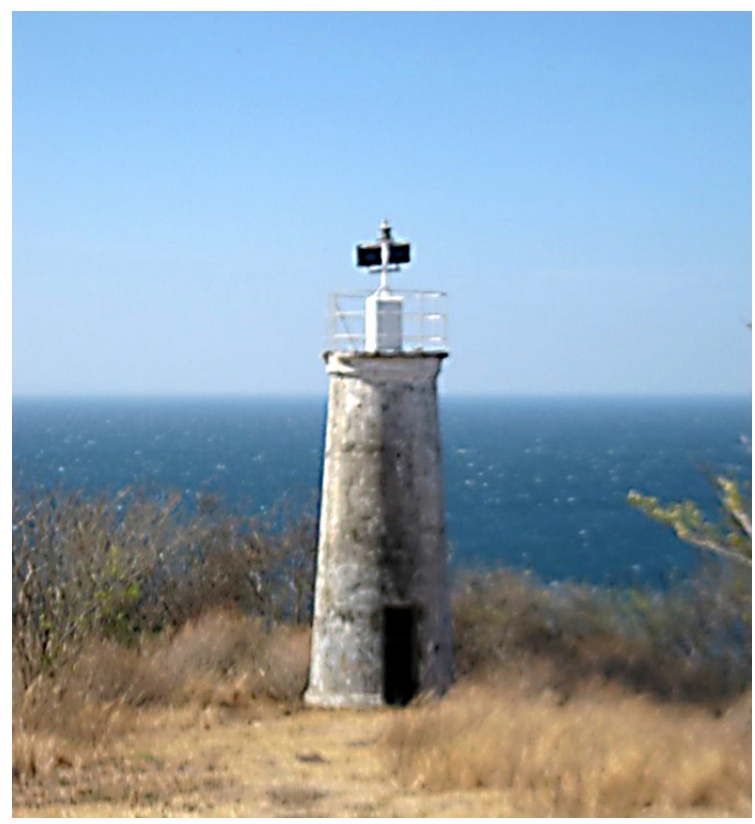

Faro del cabotaje de 1940. Foto Ramiro García 
Este conjunto de bienes patrimoniales muebles e inmuebles de San Juan del Sur reconstruyen su importante historia y son verdaderos atractivos para que la comunidad oferte nuevas rutas de turismo cultural sostenible, unidos a las prácticas que forman parte de las dinámicas artísticas y folclóricas del pueblo; que se transforman en atractivos turísticos de evento como las celebraciones religiosas de San Juan Bautista patrono de la comunidad o la Semana Santa que es muy solemne y rica en comidas, dulces y bebidas tradicionales.

\section{Turismo masivo y alternativas de desarrollo sostenible en San Juan del Sur}

A partir de la segunda mitad del siglo pasado, el turismo internacional ha registrado una gran expansión, tanto en movimiento de viajeros como en generación de ingresos y puestos de trabajo, situándose como uno de los sectores líder de la economía mundial. En la modernidad el fenómeno turístico se define como industria; describiéndolo como una actividad netamente económica-productiva; por lo que el marketing y el management se han apoderado de la finalidad del turismo. Korstanje, afirma que según este paradigma netamente instrumentalista, el turismo sigue patrones de producción y consumos específicos que tienen su origen en el ethos capitalista. (Korstanje, 2006).

Francisco Muñoz de Escalona hace una profunda crítica a los planteamientos de Korstanje, su posición sostiene que es necesario repensar el rol mercantilista del turismo y del desarrollo para establecer formas negociadas de comprensión. A diferencia de Korstanje, Muñoz de Escalona entiende que el turismo no es ni una institución social milenaria, como tampoco una actividad puramente consumista. (Escalona, 2000).

Es un hecho que la antropología abarca todas las dimensiones y contempla el fenómeno turístico desde una perspectiva holística, como un hecho social total. Más allá de la visión académica que lo restringe a una industria o un negocio, es un fenómeno que está presente en cada nivel y en cada sector de la vida social; valorando que el turismo influye en la organización del territorio, los modos de vida, la visión de nosotros y de los otros, la relación con el patrimonio cultural, los valores y las costumbres que se van imponiendo en un lugar. (Salas, 2009).
Refiriéndonos al Turismo de San Juan del sur en la modernidad, se considera uno de los principales destinos turísticos de sol y playa en Nicaragua a nivel nacional e internacional, así lo informa el Instituto Nicaragüense de Turismo (INTUR). Según estadísticas del Banco Nacional de Nicaragua (B.C.N) dice: Con base en la información de cruceros que llegaron a los puertos de San Juan del Sur y Corinto, el gasto per cápita promedio diario de los cruceristas fue mayor en San Juan del Sur que en Corinto. (B.C.N, 2018).

En una investigación de campo realizada por estudiantes y dirigida por docentes del INCAE refieren que San Juan del Sur, como municipio turístico es uno de los principales destinos de Nicaragua, pero a pesar de su potencial no cuenta con una visión diferenciadora de su oferta, indispensable para su desarrollo turístico y posicionamiento internacional. Es, además, el sitio nacional con mayor cantidad de establecimientos dedicados a la hotelería, después de la capital Managua, también existen establecimientos familiares, como viviendas particulares acondicionadas para recibir al turista. En cuanto a alimentación, hay 33 restaurantes debidamente certificados ante el INTUR, además de 28 bares. En el municipio también se encuentran establecimientos dedicados a ofrecer excursiones en el destino turístico, que juegan un rol de intermediación y guía para turistas sobre la oferta de actividades acuáticas como pesca y surf. También hay oferta de caminatas, canopy, cabalgatas, paisajismo y conducción de vehículos todo terreno. (Balladares, Padilla, Ramirez, \& Pérez, 2015). Las conclusiones de INCAE identifican que la tipología del turismo que se desarrolla en San Juan del Sur es el de sol y playa; tanto con turistas nacionales como extranjeros; con algunos atractivos eventuales dentro del turismo deportivo y turismo de aventura.

Los parámetros globalizados del turismo capitalista no son compatibles con el medio ambiente ni con las prácticas comunitarias. Los destinos turísticos que ofertan atractivos de la naturaleza, promueven el turismo masivo, porque genera grandes cantidades de ingresos, pero no dan prioridad a la conservación del medio ambiente, ni están interesados en el impacto a las comunidades; por el contrario buscan que estas poblaciones desaparezcan y cedan los espacios para construir el prototipo de planta y facilidades turísticas. 
Podemos resumir el impacto del turismo en su versión capitalista en las palabras expresadas en una entrevista en el año 2013, por Don José Jesús Lugo Tablada, poblador local de 70 años que dijo: Siento mucha nostalgia cuando recuerdo esos bellos tiempos en que estas colinas eran públicas y todos podíamos ir con libertad a observar la belleza de la playa, la puesta del sol, correr alrededor del fortín El vigía o del Faro del Cabotaje, observar las huertas de cultivo y los corrales donde pastaba el ganado en las tierras comunales de San Juan del Sur. Recuerdo, nos dice, que ahí sembraban muchos productos de autoconsumo, entre los agricultores estaba; Don Santiago Lugo, Hilario Hernández y otros; hoy en día hemos perdido la agricultura y nuestros caminos; si queremos ir a esos parajes debemos rendir muchas cuentas a un vigilante que han puesto ahí los que ahora son dueños de las colinas del Municipio. Finaliza diciendo el turismo es bueno, nos genera trabajo, pero debe ser controlado, llega demasiada gente y no queda espacio para nadie.

La gente vende a los foráneos sus casas, terrenos aledaños y San Juan del Sur está dejando de pertenecernos. Imagínate que en el Gobierno de Doña Violeta Barrios de Chamorro, decidieron mover nuestro cementerio del lugar histórico que tenía, para vender los lotes de terreno y hacer quintas, porque el cementerio estaba en un buen lugar con vista al mar, entonces la Presidenta compró un lote y mandó construir su casa, pero en el proceso de construcción empezaron a salir un montón de huesos de los difuntos que estaban en ese lugar, porque como tenían tanta prisa por construir las casonas que no le dieron tiempo a la población de desenterrar su muertos y trasladarlos al nuevo panteón; hubieran visto como lloraba la gente al ver cómo les estaban sacando los muertos. Esas cosas no deben ser así; debemos de hacer turismo, pero recordando que la gente de la comunidad también es importante. (Tablada, 2013)

El desarrollo sostenible es un concepto introducido por la Comisión Mundial sobre Medio Ambiente y Desarrollo en el informe de Brundtland en 1987, definiéndolo como aquél que satisface las necesidades del presente sin comprometer la capacidad de las generaciones futuras para satisfacer sus necesidades propias. En 1993, en la Conferencia Euromediterránea sobre Turismo y Desarrollo Sostenible, la Organización Mundial de Turismo (OMT) en el documento titulado Tourism the year 2000 and beyond qualitative aspects, definió el concepto de Turismo Sostenible como el que atiende las necesidades de los turistas actuales y de

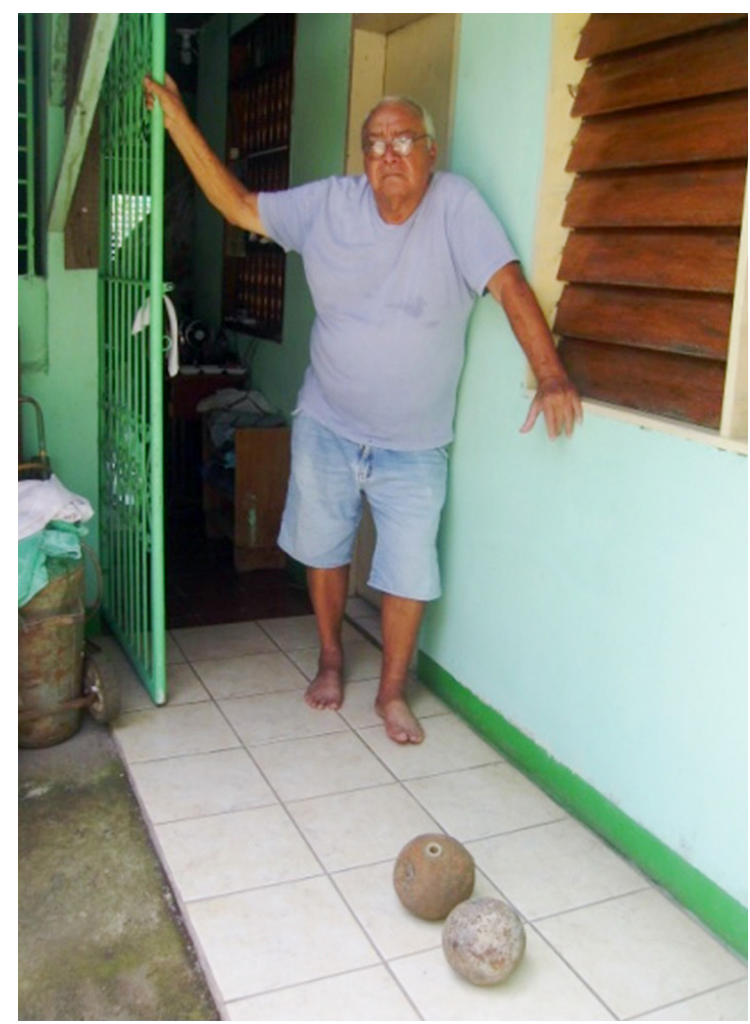

Don José Jesús Lugo Tablada. Originario de San Juan del Sur, entrevistado. Foto Sandra Espinoza

las regiones receptoras y al mismo tiempo protege y fomenta las oportunidades para el futuro. Esto se concibe como una vía hacia la gestión de todos los recursos de forma que puedan satisfacerse las necesidades económicas, sociales y estéticas, respetando al mismo tiempo la integridad cultural, los procesos ecológicos esenciales, la diversidad biológica y los sistemas que sostienen la vida. (OMT, 2000).

Desde este concepto se analiza que para que la actividad turística sea sostenible, debe permitir la sostenibilidad ecológica, es decir, que no cause cambios irreversibles en los ecosistemas del destino, igualmente valorar la sostenibilidad social, refiriéndose a la capacidad de una comunidad para absorber cierta cantidad de turistas; debe procurar la sostenibilidad cultural, tomando en cuenta que una comunidad ha de ser capaz de retener o adoptar sus propios elementos culturales que difieren de la cultura del turista y finalmente lograr la sostenibilidad económica. Desde el capitalismo, se asume que el beneficio económico debe de ser para el sector 
inversionista como las cadenas hoteleras, líneas de restaurantes, líneas aéreas; pero para las comunidades latinoamericanas la verdadera auto sostenibilidad del turismo se logra cuando los beneficios de la dinámica económica turística son recibidos por el país receptor, por la comunidad protagonista que aprovecha sus recursos naturales y culturales para el desarrollo comunitario y que al mismo tiempo protegen esos recursos.

En Nicaragua el Instituto Nicaragüense de Turismo tiene como principal línea de acción promover el turismo social comunitario, coordinando acciones con el MEFCCA para la puesta en valor de iniciativas agropecuarias familiares, emprendimientos, pequeños negocios familiares y comunitarios que tengan el potencial para ponerle valor turístico a sus actividades productivas. (INTUR, 2012). Este lineamiento re direcciona el turismo masivo de sol y playa hacia nuevas tipologías de turismo comunitario y vivencial que son tendencias que están siendo demandadas por países que quieren vivir experiencias de intercambio cultural respetuosas, reciprocas, solidarias; propias de las relaciones interculturales de los seres humanos y sus necesidades de intercambio y comunicación.

\section{Conclusión}

Referirnos a la Antropología del Turismo de San Juan del Sur es analizar los orígenes de este fenómeno en un espacio geográfico rico en recursos naturales y culturales. Un emplazamiento en el que han habitado diferentes grupos étnicos a lo largo del tiempo, por lo que en la modernidad confluyen las culturas originarias con las foráneas enriquecidas por interesantes vestigios materiales que forman su patrimonio cultural tangible mueble e inmueble y un vasto patrimonio inmaterial resguardado en la memoria colectiva de la comunidad y expresado en sus tradiciones, costumbres, mitos, expresiones artísticas, comidas, bebidas, vestuarios; entre otros. Esta riqueza inmaterial no es homogénea y no se le puede atribuir a una sola cultura; sino que es el resultado de la multiculturalidad que ha recibido San Juan del Sur desde sus orígenes hasta el presente. Consideramos que existen las condiciones adecuadas para que la comunidad de San Juan del Sur se empodere de la dinámica social - económica turística en todos los ámbitos, re direccionando el turismo masivo de sol y playa y sus impactos; hacia un turismo comunitario, vivencial, con segmentos de visitantes que se vuelven amigos de la naturaleza, la cultura y la gente de San Juan del Sur.

\section{Bibliografía}

Alemán, M. (1977). 15 Lecciones de turismo. Mexico: Consejo Nacional de Turismo.

Argibay, M. (2009). Cuadernos de trabajo Hegoa-Multiculturalidad. Valencia: S/E.

B.C.N. (2018). Encuesta de Turismo. Segundo Semestre del 2018. Managua: S/E.

Balladares, S., Padilla, M., Ramirez, L., \& Pérez, F. (2015). En la búsqueda de la competitividad del clúster turístico de San Juan del Sur. Managua: S/E.

Barrios, L. (2009). La antropología del turismo. Mexico: Universidad.

Carro, P. C. (2007). Patrimonio Cultural en identidad. Perú: ARTEGRAF.S.A.

Danglar, S. (25 de febrero de 2013). Multiculturalidad. (R. García, \& S. Espinoza, Entrevistadores)

Desola, D. L. (1977). Antropología centroamericana. Antología. Mexico: EDUCA,centroamerica.

Escalona, F. M. (2000). Autoxia del Turismo. S/C: S/E.

Gámez, J. D. (1993). Historia de Nicaragua. Managua: Hispamer S.A.

García, R. (1977). Los Patrones Alimenticios en el Pacifico Sur de Nicaragua. Quito-Ecuador: S/E.

INTUR. (2012). Instittuo Nicaraguense de Turismo. Managua: s/e.

Korstanje, M. E. (2006). Anthropology of tourism for XXIth century. Buenos Aires: Universidad de Palermo. 
Kottak, C. P. (2002). Antropología Cultural. Madrid: Madrid : McGraw-Hill.

Leslies, F. (1976). The war in Nicaragua newspaper 1855-1857. Nicaragua: Talleres y editoriales San José.

Muñiz, R. (20 de Febrero de 2017). Origenes de la comunidad de San Juan del Sur. (R. García, \& S. Espinoza, Entrevistadores)

OMT. (2000). Tourism the year 2000 and beyond qualitative aspects. S/C: S/E.

Portilla, M. L. (1972). Religión de los Nicaraos. Mexico: S/E.
Romero, M. T. (2009). Pueblos originarios: cultura y poder. Mexico: S/E.

Salas, L. á. (2009). La Antropología del Turismo. Mexico: Universidad.

Sánchez, A. (1991). Psicología Comunitaria, origen, concepto y características. Barcelona: Departamento de Psicología Social.

Sanchez, M. R. (1977). Historia de El Realejo. San José: Talleres de Editorial y Litografía San José.

Tablada, J. J. (10 de marzo de 2013). La multiculturalidad. (R. García, \& S. Espinoza, Entrevistadores)

\section{Ramiro García Vásquez}

Realizó estudios de Licenciatura en Ciencias de la Educación con Mención en Biología (UNAN-Managua). Posteriormente hizo estudios Técnicos en el extranjero (México, Panamá, Suecia, Dinamarca) se especializó en Paleontología, Arqueología y Antropología Física. Entre 1994 y 2013 se desempeñó como Responsable del Departamento de Investigaciones Antropológicas del Museo Nacional de Nicaragua, realizó investigaciones paleontológicas, antropológicas y arqueológicas a nivel nacional. En el año 2001 fue condecorado con la Medalla Diocleciano Chávez y Las Llaves del Museo Nacional de Nicaragua en reconocimiento a su labor científica. Es miembro Honorario de la Academia de Geografía e Historia de Nicaragua. En los últimos 15 años se ha desempeñado como Consultor Cultural a nivel nacional e internacional.

\section{Sandra Verónica Espinoza}

Realizó estudios de Licenciatura en Administración turística (1999), posteriormente (2002) estudió un Técnico Superior en el Instituto Nacional Tecnológico de Nicaragua en Administración de la Cultura. Entre 2009 y 2010 hizo un Diplomado en Pedagogía de la Formación Profesional en la Universidad de Don Bosco, San Salvador, El Salvador. De 2000 a 2003 se desempeñó como Subdirectora del sitio León Viejo (Patrimonio Mundial). Del 2006 al 2014 fue directora del Museo Chorotega-Nicarao (Chinandega). De 2005 al 2014 trabajó como docente de Área Técnica o Formación Profesional. A partir del 2005 empezó a trabajar como consultora en temas turísticos, culturales y sobre liderazgo. Actualmente está cursando la Maestría en Antropología y Liderazgo Social. 